\title{
NOTAS
}

\section{Sobre nombres propios imaginarios que expresan acción, situación \\ o pensamiento}

Una idea muy antigua, pero que renovó y perfeccionó $H$. Usener, es la de que muchos dioses de los griegos y romanos era «dioses de acción»(Sondergötter»): tesis funcionalista en esencia, que puede apoyarse también en criterios lingüísticos. Bastantes nombres de dioses latinos -en efecto- aludían a acciones humanas comunes e incluso triviales. Esta idea da que pensar en términos más generales y, si se quiere, también vulgares. En efecto, desde hace mucho tiempo, en lengua castellana, se usa de una cantidad considerable de expresiones para reflejar, mediante nombres imaginarios, una acción, situación o un pensamiento.

Dejando a un lado las referencias esporádicas que puede haber a tales nombres en obras de Cervantes, Lope, etc., existe cierto texto bastante largo, debido a Quevedo, que recoge muchos de ellos. Se trata del titulado El sueño de la Muerte (1622) que, después (desde 1631) es más conocido por Visita de los chistes: objeto también de revisión, con expurgo, del autor mismo '. Allí se recogen, según mi cuenta, no menos de cuarenta y cinco nombres de éstos, con comentario de longitud desigual en el que, a veces, se aclara el uso o se ilustra con ejemplos. Hallamos, así, a «Juan de la Encina», «El rey que rabió», «El rey Perico», «Mateo Pico», «Agrajes», «Arbolías», «Chisgaravís», «Pero Grullo», «El Otro», «Cierta persona», «No se quién», «Cierto autor», «Calaínos», "Cantimpalos», «Dueña Quintañona», «Álvarez» (a la que se llama), «La dueña», «Don Diego de Noche», «Cochitehervite», "Trochimochi», «Doña Fáfula», «Mari-Zápalos», «Mari Rabadilla», «Garibay», «Perico de los Palotes», «Pateta», «Juan de las calzas blancas», «Pedro por demás», «El bobo de Coria», «Pedro de Urdemalas», «Santo Macarro», «Santo Leprisco», «San Ciruelo», «Santo de Pajares», "Fray Jarro», «San Porro», «Villadiego», «Vargas», «La manceba del abad», «Matalascallando», «Matalashablando», «Lanzarote», «Juan de buen alma», «Juan Ramos», «Sastre del Campillo»

Obras completas, ed. de Felicidad Buendía. Obras en prosa (Madrid, 1988), I, pp. 193-220. 
y «Diego Moreno». Según se ve, la mayoría se dan como nombres propios; son personificaciones y símbolos de acción, de modos de actuar o de pensar. Parte considerable siguen siendo conocidos en castellano actual: unos resultan más usuales que otros.

Es provechoso comparar la serie recogida en el siglo XVII con la que da el erudito sevillano Luis Montoto y Rautenstrauch en una obra que se publicó en 1888 y en Sevilla, llamada Un paquete de cartas. De modismos, locuciones, frases hechas, frases proverbiales y frases familiares. Son hasta setenta y tres. Se repiten bastantes de los de Quevedo, más algunos, que parecen de acuñación posterior o de uso local. He aquí la lista: «Ambrosio» (el de la carabina), «Perico de los palotes», «El sastre del Campillo», «Pero Grullo», «El barquero de las verdades», «El pastor de las verdades», «El hombre de palo», «Picio», «Maricastaña», «El bobo de Coria», «El sargento de Utrera», «El Tostado», «Agrajes», «Los nueve de la fama», "Carracuca», "Los novios de Hornachuelos», «El rey que rabió», «El rey Perico», «El preste Juan de las Indias», «Calaínos», «Vargas, el averiguador», «Villadiego», «Gálvez», «Cachidiablo», «El gobernador de Cartagena», «Pateta», «Garibay», «Juan Lanas», «Juan soldado», «El santo de Pajares», «Briján», «Calepino», «Vicente» (el de la gente), «Blas» (el punto redondo), «Caco», «Fulano», «Zutano», «Mengano», «Perengano», «Merlín», «Marica en Ravena», «Orbaneja» (el del «gallo»), «Mauleón», «Amaro Rodríguez», «El gallo de Morón», «El general no importa», «La judía de Zaragoza», «Fray Modesto», «Los Fúcares», «El mayo de Portugal», «Beltrán», «Antón Perulero», «Diego Moreno», «El tío Perete», «Callejas», «Marisabidilla», «La Pepa», «La dama de la media almendra», «Perencejo», «Don Diego de Noche», «Don Diego de Día», «El pastor de Mejorana», «Periquito entre ellas», «Facundo», «Juan de las Viñas», «Juan Perdemás», «El niño Zangolotino», «La Perala», «El tío Paco con la rebaja», «Carracuca», «La Tana», «Juan de la Encina», «Juan de la Torre», «El enano de la venta».

Hay, desde luego, zonas de España en que no son familiares y otros parecen ideados por lo menos en puntos conocidos o referidos a un término preciso. Tanto Quevedo como Montoto ilustraron el uso de estas expresiones e incluso procuraron explicar su origen en algún caso. Tarea poco fácil y que se presta a fantasear. De todas maneras conviene subrayar lo repetido que es el hecho de que una situación o carácter dé lugar a la personificación o personalización.

El pensamiento vulgar y tautológico se atribuye a Pero Grullo, personaje imaginario: en francés, sin embargo, el representante del mismo es una famosa personalidad del pasado: Mr.-de la Palice o la Palisse (muerto en 1525), valiente guerrero sobre el que se «colgó» la reputa- 
ción de modo harto complicado al parecer, arrancando de una canción que, en su origen, no se refería a él probablemente y que fue ampliada en el siglo XVIII ${ }^{2}$.

En la serie española hay también algunos personajes históricos conocidos y que se presentan, con mayor razón, como símbolos. Por ejemplo los «Fúcares» que lo son de la riqueza. La firma Fugger fue conocida como de gran potencia económica desde la época de Juan que actuó a partir de 1376 y murió en 1409. Sus descendientes florecen durante la primera mitad del siglo XVI. Los «Fúcares» tienen calle en Madrid singularizada: la del «Fúcar».

Otras figuras de la colección son conocidas en textos literarios, anteriores al de Quevedo. Así en el Viaje de Turquía de Cristóbal de Villalón, el vallisoletano, salen hablando «Juan de Voto a Dios», «Mátalas callando» y «Pedro de Urdemalas» que es el propio autor. En el «apellido» se expresa carácter malévolo ${ }^{3}$. Por otra parte, como es sabido, Pedro de Urdemalas, es personaje utilizado por Cervantes en la Comedia famosa de Pedro de Urdemalas ${ }^{4}$. Correas en la sección de frases proverbiales nos dirá que «es tenido por un mozo que sirvió muchos amos y a todos hizo muchas burlas y a otros muchos»'. Por cierto que esta obra es una mina valiosa para el estudio del tema que nos ocupa. Porque allí aparecen otros «Pedros» como «Perico de los Palotes» ${ }^{6}$ o «Pero Grullo» 7 y «Pateta» ${ }^{8}$ y por otra parte «Maricastaña», una mujer de tiempo muy antiguo: "cuando hablaban los animales y las aves y aun peñas, y montes y árboles» '; ésta en la serie de las Marías: «Marisincasa» ${ }^{10}$, «Marisabidilla» ${ }^{11}$, «Marizárpalos» ${ }^{12} \mathrm{y}$ aun «Marirrabadilla» ${ }^{13}$.

2 Se puede leer en el artículo correspondiente del Grand dictionnaire universel $d u X^{\prime} X^{e}$ siècle, de Pierre Larousse (Paris, s. a.), X, p. 179a, $b, c$.

3 Viaje de Turquia, en Autobiografías y memorias, N.B.A.E., II, p. 5.

4 Comedias y entremeses, edición de R. Schevill y A. Bonilla (Madrid, 1917), III, pp. 117-228.

5 Vocabulario de refranes y frases proverbiales (1627), ed. de Louis Combet (Burdeos, 1967), p. 7216 .

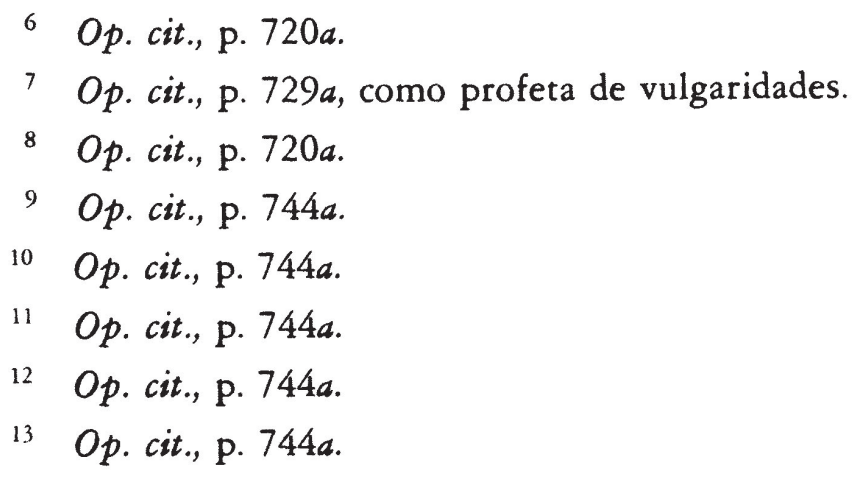


Hay nombres despectivos de profesión, como el de los médicos $\left(«\right.$ Matasanos») ${ }^{14}$ y que aún está en uso. Existen también otros nombres despectivos de tradición despectivos de tradición literaria, como el de' «Trotaconventos»: dicho en baldón, con nota de alcahueta ${ }^{15}$, que arranca de la obra del Arcipreste de Hita.

De texto literario famoso también, arranca la expresión «casa de Lazarillo» ${ }^{16}$. Hay, por lo demás, alguno con mucha resonancia legendaria, como el de «Merlín», el mago del ciclo artúrico, que tuvo gran popularidad en España, como es sabido. Por otra parte, surgen otros como el del «Preste Juan de las Indias», que corresponden a una vieja Geografía legendaria y también los hay que, en un momento determinado, quedan adscritos a un ser humano, como el «Bobo de Coria», al que retrató Velázquez, en su serie patética de tontos, deformes y locos que «amenizaban» el antiguo alcázar de Madrid, siendo él pintor de Felipe IV.

Por otra parte, en las dos listas dadas falta algún nombre, como «Don Nadie», «Un quidam», el «Muy conocido en su casa a las horas de comer», la «Señorita del pan pringao», «Don Hermógenes» y «Tragaldabas». Podrían añadirse otros: varios de tradición literaria, como «El licenciado Cabra» o «El licenciado Vidriera». Algunos locales e incluso fugaces ¿Quién se acuerda hoy en Madrid de «Madame Pimentón»? Hay también nombres propios que se repiten, para destacar su carácter común, vulgar. El más repetido es el de Juan: «Juan Lanas», «Juan soldado», «Juan de las Viñas», «Juan de la Encina», «Juan de la Torre», «Juan Perdemas», «Juan de Voto a Dios». En segundo lugar va Pedro, Pero o Perico. Como nombres comunes se repite asimismo el de «El rey...» ${ }^{17}$ y no faltan apodos, como el de EEl Tostado». En última instancia estos nombres imaginarios que expresan una acción (o falta de ella), plantean también el problema de si en el origen de algunos de ellos no había razones puramente auditivas, como ocurre en cierto caso que cuenta Huarte de San Juan en un texto que transcribo a continuación:

De esta opinión de Platón fue un caballero español, cuyo entretenimiento era escribir libros de caballerías, porque tenía diferencia de imaginativa, que convida al hombre a ficciones y mentiras. De este se cuenta que, introduciendo en sus obras un gigante furioso, anduvo muchos días imaginando un nombre que respondiese enteramente a su brabosidad y jamás lo pudo encontrar; hasta que ju-

\footnotetext{
14 Op. cit., p. $746 b$.

15 Op. cit., p. 7396 .

16 Op. cit., p. 702b, por chica, ruin y de mal aliño.

17 Correas, op. cit., p. 751b, «Rey Grillo», «Rey Perico», «Rey Pepino», «Rey
} Mandinga». 
gando un día a los naipes en casa de un amigo suyo, oyó decir al señor de la posada (ola muchacho, traquitantos a esta mesa). El caballero, como oyó este nombre Traquitantos. luego le hizo buena consonancia en los oídos, y sin más aguardar se levantó diciendo: «señores, yo no juego más, porque ha muchos días que ando buscando un nombre que cuadrase con un gigante furioso que introduzco en estos borrones que compongo, y no lo he podido hallar hasta que vine a esta casa donde siempre he recibido toda merced» 18 .

Por último, convendrá recordar asimismo que ciertos procesos de personificación o personalización son conocidos desde antiguo con respecto a fiestas o fechas del año, como el Carnaval o la Cuaresma y que también se han dado en relación con movimientos religiosos y sociales de suerte que la tendencia colectiva se explica en función del nombre de un supuesto fundador, que lleva, precisamente, el nombre que se le daba a la misma tendencia. Resulta, así por ejemplo, que el nombre con que se conocían a sí mismos algunos secuaces de Cristo, que se consideraban los depositarios más puros de su doctrina, el de «ebionim» ('pobres', en hebreo) produjo el de «Ebion» que se consideró el de un fundador de secta: los ebionitas. Otro tanto ocurre con «Masbotheo» como fundador de los "masbotheos»". Unos procesos distintos son los que hacen que un personaje literario sea tomado como modelo de un vicio. Así Shylock o Harpagon, de la avaricia, Tartufo, de la hipocresía. También de una condición exagerada incluso buena, como cuando se habla de alguien y se dice que es un Quijote o de una acción quijotesca o cuando por lo contrario, se la califica de sanchopancesca. Existe también el arquetipo del Don Juan. Pero con frecuencia se ha intentado perfilarlo como si fuera un ser real. Los médicos han sido muy dados a hacerlo y así ha habido quienes le han asignado rasgos feminoides, etc. Un exceso de tantos. Porque por esta vía podríamos llegar a describir en términos físicos a Pero Grullo o a Maricastaña.

\section{julio Caro Baroja}

18 Juan HuARte de SAN JUAN, Examen de ingenios para las ciencias (Madrid, 1846), pp. 131-132 (capítulo X).

19 E. RenAN, Les Évangiles et la séconde génération chrétienne (Paris, "1923), pp. $45-46$. 